\begin{tabular}{cc}
\hline & \\
&
\end{tabular}

\title{
Merkel Cell Carcinoma of Anal Canal: Case Report and Literature Review
}

Zahrh F Abualsaud ${ }^{1}$, Zahra F Alkhunaizi ${ }^{2}$, Mohammed Somali ${ }^{2}$, Amani Joudeh ${ }^{2}$, Mohammed Tahtouh $^{1}$

${ }^{1}$ Dept of General Surgery, King Fahad Specialist Hospital Dammam, Saudi Arabia:

${ }^{2}$ Dept of Pathology, King Fahad Specialist Hospital Dammam, Saudi Arabia:

\section{ABSTRACT}

Few cases of anal canal Merkel cell Carcinoma have been reported in the literature. Merkel Cell Carcinoma is rare neuro- Zahrh F Abualsaud endocrine tumor which commonly found in sun-exposed areas abualsaud.zahrh.f@gmail.com such as extremities. We describe a case of 74-year-old male with anal canal Merkel Cell Carcinoma. He presented with perianal pain, tenesmus and itching. Besides, he was found to have chronic anemia. An anal nodule was found during per-rectum physical examination that was excised during endoscopy. HisHow to cite this article:

Zahrh F Abualsaud, Zahra F Alkhutological examination of the nodule confirmed the diagnosis of Joudeh, Mohammed Tahtouh. Merkel Cell Carcinoma. Thenceforward, patient died 7 months Merkel Cell Carcinoma of Anal Caafter diagnosis with marked metastatic disease despite initiation nal: Case Report and Literature Reof Pembrolizumab therapy. view. International Journal of Case Reports, 2021, 5:245.

Keywords: Anal canal; Merkel cell carcinoma; Neuroendocrine tumors; MCC

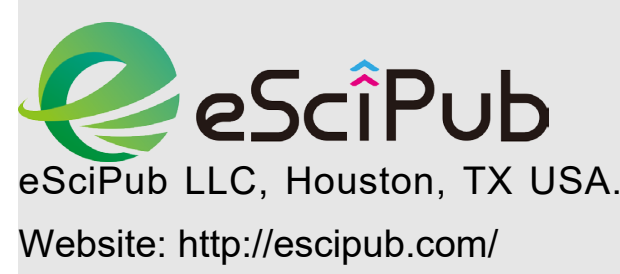




\section{Case Report:}

We are reporting a case of 74-year-old gentleman, known to have DM-type2 on insulin, HTN, Hypothyroidism, with middle-eastern ethnicity, presented to our colorectal Surgery clinic with 8 months history of peri-anal pain, tenesmus and itching. Patient gave history of chronic anemia prior to his present complaint. His basic blood workup was within normal limits, last Haemoglobin level was $11.3 \mathrm{~g} / \mathrm{dL}$ and CEA was $0.77 \mathrm{ng} / \mathrm{mL}$. HIV screening, Hepatitis Profile and QuantiFERON TB test were all negative.

Physical Examination showed a 1-cm nodule at anal verge with intact anal tone. The nodule was excised during endoscopy.

Histologic sections of the nodule revealed anal squamous epithelium with sub-epithelial infiltration by blue round cell tumor characterized by sheets, nests and trabeculae of loosely cohesive neoplastic cells that were intermediate in size and exhibited high nuclear to cytoplasmic ratio, relatively finely speckled chromatin and inconspicuous nucleoli. Rare rosette like structures were seen. Numerous mitotic figures and apoptotic bodies were noticed. The neoplastic cellular infiltrates were admixed with numerous small mature lymphocytes.

Immunohistochemical stains were performed on formalin-fixed paraffin-embedded sections using ultra-view universal DAB detection system from FDA approved Ventana automated staining platform. The neoplastic cells displayed the classical Cytokeratin 20 perinuclear dot-like staining pattern and they were diffusely positive for Synaptophysin, Chromogranin, CD56 and P16 stains. The neoplastic cells were negative for P63, CDX2, CK7, TdT, and CK5/6. CD3 immunostaining showed background $\mathrm{T}$ cells lymphocytes with $(2: 1)$ CD4:CD8 ratio. Henceforth, a diagnosis of Merkle Cell Carcinoma (MCC) was made (Fig. 1).
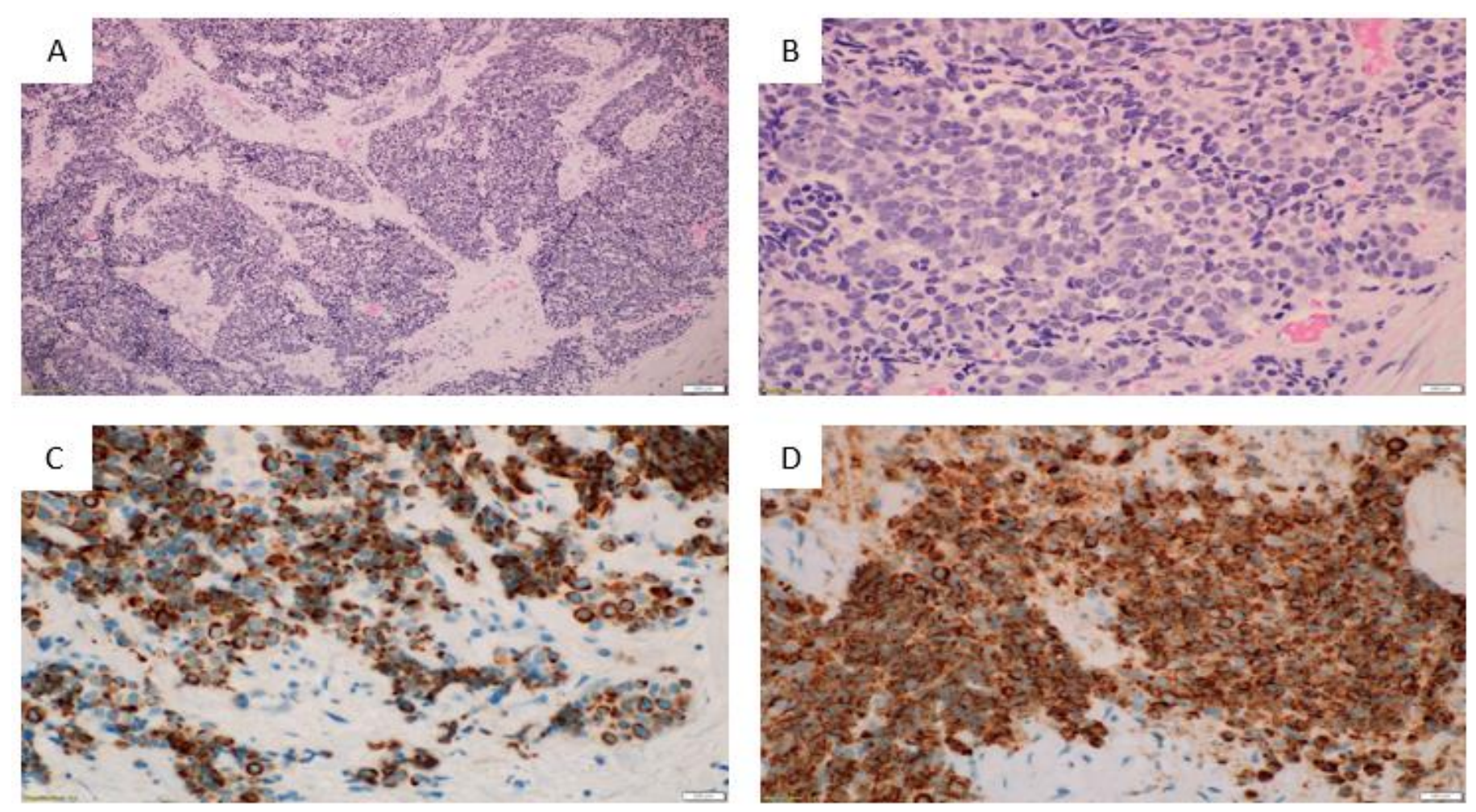

Figure 1. A-Histological examination revealed sheets and nests of round blue cells ( $H \& E \times 100)$. $\mathrm{B}$ - the tumor cells were intermediate with scant cytoplasm, nuclear molding, dispersed chromatin. Necrotic cell debris was present with small mature lymphocytes in between (H\&Ex400). CParanuclear dot-like staining pattern for CK20(Immunohistochemistry $\times 200$ ). D- The neoplastic cells showed diffuse granular cytoplasmic staining for Synaptophysin (Immunohistochemistry $\times 200$ ). 
Further investigation through computed pulmonary, hepatic, and splenic nodules; tomography scan (CT scan) of Chest, Abdomen, suspicious for metastasis. All of which showed and Pelvis showed multiple enlarged lymph FDG-uptake on positron emission tomography nodes all over the body along with multiple scan (PET scan). (Fig. 2.A).
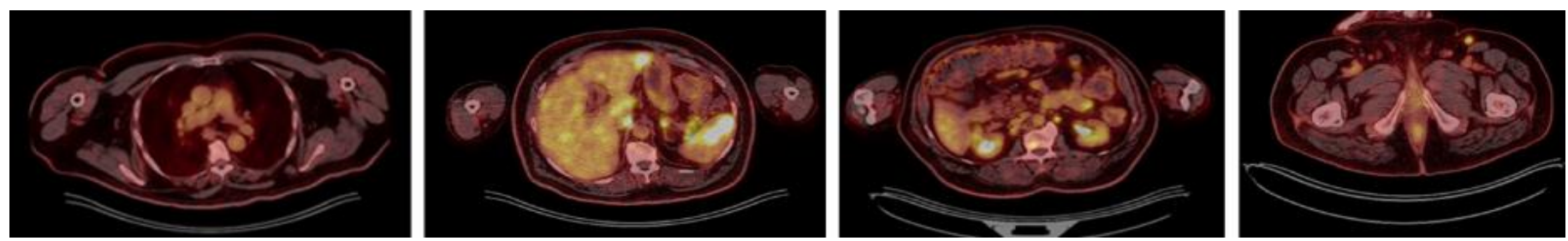

Figure (2.A): PET SCAN of Chest, Abdomen, Pelvis prior to treatment, shows FDG avid lesions in multiple focal hepatic, splenic lesions with enlarged lymph nodes in retroperitoneal, paraaortic, aorto-caval, common iliac and external iliac groups, along with L2 vertebral body.
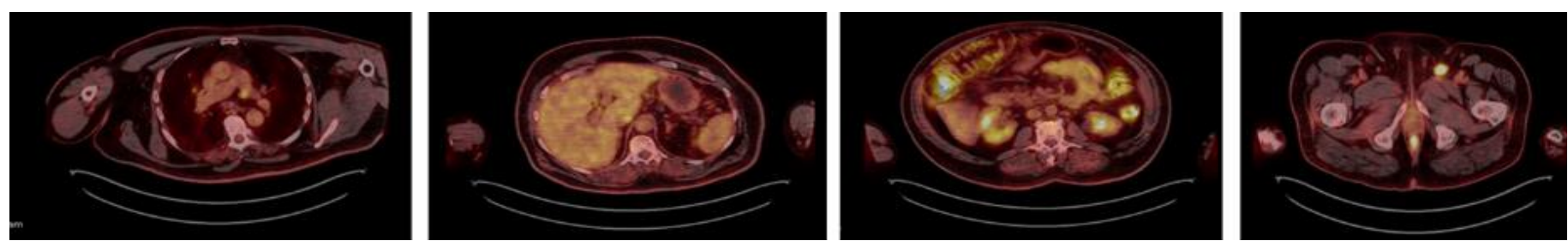

Figure (2.B): PET SCAN of Chest, Abdomen, Pelvis after receiving Pembrolizumab. It showed significant resolution of hepatic, splenic, L2 vertebra, and interval improvement of large left inguinal lymph nodes and multiple pulmonary nodules, consistent with metastasis.

\begin{tabular}{|c|c|c|c|c|c|}
\hline YEAR & AUTHER & $\begin{array}{c}\text { PATIENT } \\
\text { BACKGROUND }\end{array}$ & $\begin{array}{c}\text { CLINICAL } \\
\text { PRESENTATION }\end{array}$ & Diagnosis & OUTCOME \\
\hline 2003 & $\begin{array}{l}\text { Peterson } \mathrm{C} \text { and } \\
\text { colleagues }[4]\end{array}$ & $\begin{array}{l}\text { 42-year-old } \\
\text { Female }\end{array}$ & $\begin{array}{l}\text { Haemorrhoids during } \\
\text { pregnancy }\end{array}$ & MCC of the anal canal & $\begin{array}{l}\text { Passed away due to advanced } \\
\text { liver metastasis after } 13 \text { months } \\
\text { of } D x\end{array}$ \\
\hline 2004 & $\underset{[20]}{\text { Limei Guo et al. }}$ & $\begin{array}{l}80 \text {-year-old } \\
\text { Male }\end{array}$ & $\begin{array}{l}\text { Painful fixed mass in } \\
\text { anal canal }\end{array}$ & $\begin{array}{l}\text { Anal NEC with } \\
\text { pagetoid extension }\end{array}$ & Not mentioned \\
\hline 2011 & $\begin{array}{l}\text { E J S Ong and } \\
\text { colleagues [21] }\end{array}$ & $\begin{array}{l}\text { 43-year-old } \\
\text { Male, HIV- } \\
\text { positive }\end{array}$ & $\begin{array}{l}\text { Ulcerating mass in anal } \\
\text { canal }\end{array}$ & $\begin{array}{l}\text { Synchronous MCC and } \\
\text { SCC }\end{array}$ & $\begin{array}{l}\text { Wide spread metastasis to whole } \\
\text { body, passed away after } 8 \text { weeks } \\
\text { of Dx. }\end{array}$ \\
\hline 2012 & $\begin{array}{l}\text { Ohtomo R et al. } \\
\text { [22] }\end{array}$ & $\begin{array}{l}\text { 70-year-old } \\
\text { Female }\end{array}$ & $\begin{array}{l}\text { Submucosal tumor at } \\
\text { dentate line }\end{array}$ & $\begin{array}{l}\text { Anal canal NEC } \\
\text { associated with } \\
\text { squamous } \\
\text { intraepithelial } \\
\text { neoplasia }\end{array}$ & $\begin{array}{l}\text { Underwent APR, emergence of } \\
\text { bilateral Pulmonary and bone } \\
\text { metastasis, received palliative } \\
\text { Radiotherapy, passed away after } \\
2 \text { years of Dx }\end{array}$ \\
\hline
\end{tabular}

carcinoma

Hence, the patient's disease stage was stage IV disease [ Metastatic Neuroendocrine Carcinoma]. Subsequently, he started the first dose of Pembrolizumab with 3 weeks interval per session in June,25,2020. During his treatment course, he was suffering from constant vague pains around anal verge. So, a trial of Pelvic Palliative Antalgic Radiotherapy to Anal Canal at dose of 8 Gy in 1 Fraction was successful for pain relief.
Follow-up PET-scan was done after 5 cycles of Pembrolizumab showed mixed response with overall progression by development of new metastatic foci in both lungs and large left inguinal lymph nodes. Afterward, his disease was markedly progressed with rectal involvement and osseous metastasis of right acetabulum and bilateral iliac bones that was discovered in follow-up MRI (Magnetic 
resonance imaging). Thenceforth, the patient died in about 7-months from diagnosis.

\section{Introduction:}

Merkel Cell Carcinoma (MCC) is rare nonmelanomatous cutaneous tumor of neuroendocrine origin with incidence of 0.79 per 100,000 population ${ }^{[1]}$. It was previously known as trabecular carcinoma and was initially described by Toker., et al in $1972^{[2]}$. It has an aggressive clinical course with high risk of recurrence and metastasis. The recurrence rate is around two to three years after initial diagnosis and the two-years survival rate is $28 \%{ }^{[3]}$.

MCC usually arises in sun-exposed areas, like head \&neck and extremities and to lesser extent in atypical locations as trunk, buttock, vulva, scrotal-sac and perianal region in which MCC shows an aggressive behaviour ${ }^{[4]}$.

Polyoma Virus infection plays a major role in the pathogenesis of MCC, in about $80 \%$ of MCC ${ }^{[5]}$.

Recently, the incidence of MCC is increasing. Most probably due to advances in diagnostic techniques, the growing elderly population and larger number of Immunosuppressed patients.

Unfortunately, the MCC prognosis is found to be poor compared to other tumors, due to rarity and lack of prospective randomised trials for optimum treatment protocol ${ }^{[6]}$. In addition, it is usually mistaken clinically for haemorrhoids which delay the diagnosis ${ }^{[4]}$.

However, the histological diagnosis of MCC is challenging due to histopathological features similarities between MCC and other poorly differentiated tumors such as small cell carcinoma, lymphoma, Ewing sarcoma, melanoma, and basal cell carcinoma ${ }^{[7]}$.

To the best of our knowledge, this is the fifth case of Merkel cell Carcinoma of the anal canal in the English literature.

\section{Discussion:}

Merkel Cell Carcinoma is rare, clinically aggressive cutaneous tumor that is related to advanced age, immunosuppression, ultraviolet light exposure and Polyomavirus infection ${ }^{[3,5] \text {. }}$
To date, the pathogenesis of MCC has not been extensively studied and the exact origin of Merkel cells has been a point of debate for many years, with recent suggestions of pre-B cell lymphoid origin, as demonstrated by a study of 21 cases by Jankowski, et al. ${ }^{[8]}$.

Merkel cell polyomavirus (MCPyV) is considered to play a significant role in the development of MCC and first discovered in 2008 by Feng, et al. MCPyV is non-enveloped double-stranded DNA virus of a-polyomavirus genus and considered as skin flora that rarely causes MCC. Small T antigen and truncated large T antigen of MCPyV genome promote MCC oncogenesis. Some studies show that MCPyV-positive MCC has favorable prognosis $[5,9,10]$.

The MCC clinical presentation is non-specific including perianal pain with tenesmus. MCC occurs more commonly in elderly males ${ }^{[11]}$.

Upon Physical Examination, an ulcerating mass is the most common finding. Biopsy and histological examination are the definitive method for diagnosis of MCC ${ }^{[4]}$.

The Merkle cells are normally found in the epidermis adjacent to the nerve axons ends and they function as mechanoreceptors or chemoreceptor ${ }^{[3]}$. Histology, they displayed as small round blue cells with finely speckled chromatin arranged usually in trabecular pattern. Ultra-structurally, they have dense granules at the cytoplasmic membrane. These granules can be demonstrated by immunohistochemical stains like neuroendocrine marker synaptophysin and chromogranin. Characteristically, they typically show paranuclear dot-like staining with cytokeratinin20 (CK20) which helped to differentiate MCC from other malignancies like Ewing sarcoma, small cell carcinoma and lymphoma ${ }^{[12]}$. Presence of a strong intratumoral CD8 and CD4 lymphocytes is considered in some studies as an independent predictor of survival ${ }^{[5,13]}$.

Genetically, MCC commonly showed loss of chromosomes 3p, 4, 5q, 7, 10, and 13, and extra-copies of chromosomes $1,3 q, 5 p$, and 
6. Moreover, they exhibited loss of RB1gene region and amplification of that found in L-Myc oncogene which is closely related to neuroendocrine tumors ${ }^{[14]}$.

Further workup with CT-CAP and PET-Scan is held for staging. The identification of distant metastases during staging can alter the risk-tobenefit assessment of highly aggressive local and regional treatment plans.

The prognosis of MCC is poor with distant metastasis. Nevertheless, it is strongly related to lymph node metastasis ${ }^{[3]}$. A meta-analysis of data of 122 patients from some centers found that MCC recurred within 3 years in around 60\% of patients with a positive sentinel lymph node biopsy (SLNB) vs. $20 \%$ with a negative SLNB [15]. Lymph node metastasis reported by Coquard R. et al, in around $80 \%$ of the patients with recurrent MCC [16].

About $50 \%$ of patients with MCC develop metastasis during their disease course ${ }^{[10]}$. Liver, lung, and bone are considered the most common sites for MCC metastasis [17]. The disease associated mortality rate of MCC is $46 \%$ [18]. Harms $\mathrm{Kl}$ et al, described 5-year survival rates for local, nodal, and distant disease of MCC as follows 51\%, 35\%, and $14 \%$, respectively ${ }^{[19] .}$

Upon literature review, 4 reported cases of MCC of anal canal were found. (Table. 1). ${ }^{[4,20-22]}$

Hence, the approach for MCC is multimodality due to lack of guidelines, ranging from surgery to Radiation therapy, Chemotherapy and Biological agents.

With Exception of the above-mentioned cases, most of the published literature related to MCC management was for non-anal canal tumors. The initial treatment modality was surgical excision with negative margins, followed by either follow-up or radiotherapy.

Regarding the initiation of an adjuvant radiotherapy after surgical excision, a study reviewed the Memorial Sloan-Kettering Cancer Centre's MCC database and identified 251 patients who had been treated between 1970 and 2002. [23]. It analysed patient, tumour, and treatment-related factors for their association with recurrence and survival, but no association was found between irradiation and loco-regional control [24].

In addition, there was a one randomised control trial to date comparing excision with Radiotherapy versus excision with observation showed no overall survival improvement with adjuvant Radiotherapy, but concluded a significant reduction in regional recurrence [25].

Chemotherapy has been reported to be used with or without surgery and/or Radiotherapy for stage IV i.e. cases with distant metastases (M1), it is also being considered for selected cases of macroscopic regional disease (N1b or N2) ${ }^{[26,27]}$. Nowadays, Immunotherapy is an emerging treatment with promising results, especially Immune checkpoint inhibitors that have been able to achieve durable cures in patients with certain tumor types by reactivating antitumor cellular immune responses.

One of the mechanisms of action of these agents is facilitated by the binding of PD-L1 to PD-1 on cytotoxic $T$ cells which will inhibit their tumorkilling activity. PD-L1 is frequently expressed on MCC tumor cells and peritumoral immune cells. Pembrolizumab is an anti-PD-1 antibody approved for the treatment of melanoma and non-small cell lung cancer. At least one patient with MCC showed a response to pembrolizumab during a phase I trial. A small ongoing phase II trial of pembrolizumab as a first-line treatment for advanced MCC recently reported a $71 \%$ initial response rate among 17 evaluable patients ${ }^{[28,29,30] \text {. }}$

\section{Conclusion:}

Merkle Cell Carcinoma is aggressive neuroendocrine tumor that is extremely rare and aggressive in the anal canal with tendency for distant metastasis at time of diagnosis. Hence, the MCC should be included in the differential diagnosis of anal canal tumors. Further studies are recommended to establish treatment guidelines and long-term prognosis. 


\section{References:}

[1]. Fitzgerald TL, Dennis S, Kachare SD, Vohra NA, Wong $\mathrm{JH}$, Zervos EE. Dramatic increase in the incidence and mortality from Merkel cell carcinoma in the United States. Am Surg. 2015;81:802-806.

[2]. 24. Toker C. Trabecular carcinoma of the skin. Arch Der- matol 1972;105:107-10.

[3]. Rockville Merkel Cell Carcinoma Group. Merkel Cell Carcinoma: recent progress and current priorities on etiology, pathogenesis, and clinical management. J Clin Oncol. 2009 Aug 20;27(24):4021-6.

[4]. Paterson C, Musselman L, Chorneyko K, Reid S, Rawlinson J. Merkel cell (neuroendocrine) carcinoma of the anal canal: report of a case. Dis Colon Rectum. 2003;46(5):676-678. doi:10.1007/s10350-004-6630-1

[5]. Feng H, Shuda M, Chang Y, Moore PS. Clonal integration of a polyomavirus in human Merkel cell carcinoma. Science. 2008;319 (5866):1096-100.

[6]. Emma Ramahi, B.A., Jehee Choi, B.S., Clifton D. Fuller, M.D., Ph.D., Tony Y. Eng, M.D. Merkel Cell Carcinoma. Am J Clin Oncol. 2013 June ; 36(3): 299-309. doi:10.1097/COC.0b013e318210f83c.

[7]. Poulsen M. Merkel cell carcinoma of the skin. Lancet Oncol 2004;5:593 - 9

[8]. Jankowski $M$, Kopinski $P$, Schwartz $R$, Czajkowski R. Merkel cell carcinoma: is this a true carcinoma? Experimental Dermatology. 2014;23 (11):792-4.

[9]. Haley CT, Mui UN, Vangipuram R, Rady PL, Tyring SK. Human oncoviruses: Mucocutaneous manifestations, pathogenesis, therapeutics, and prevention: Papillomaviruses and Merkel cell polyomavirus. J Am Acad Dermatol. 2019 Jul;81(1):1-21. doi: 10.1016/j.jaad.2018.09.062. Epub 2018 Nov 28. PMID: 30502418.

[10]. Schrama D, Ugurel S, Becker JC. Merkel cell carcinoma: recent insights and new treatment options. Curr Opin Oncol. 2012; 24:141-149.

[11]. Huang WS, Lin PY, Lee IL, Chin CC, Wang JY, Yang WG. Metastatic Merkel cell carcinoma in the rectum: report of a case. Dis Colon Rectum. 2007 Nov;50(11):1992-5. doi: 10.1007/s10350006-0879-5. PMID: 17713819.

[12]. Sidhu GS, Chandra P, Cassai ND. Merkel cells, normal and neoplastic: An update. Ultrastruct Pathol. 2005;29:287-294.

[13]. Han SY, North JP, Canavan T, Kim N, Yu SS. Merkel cell carcinoma. Hematol Oncol Clin North Am. 2012;26:1351-1374.
[14]. Paulson KG, Lemos BD, Feng B, et al. Array$C G H$ reveals recurrent genomic changes in Merkel cell carcinoma including amplification of L-Myc. J Invest Dermatol. 2009;129:15471555.

[15]. Gupta SG, Want LC, Penas PF, et al. Sentinel lymph node biopsy for evaluation and treatment of patients with Merkel cell carcinoma. Arch Dermatol. 2006;142:685-690.

[16]. Coquard R. Merkel cell carcinoma of the anal canal: importance of radiotherapy. Dis Colon Rectum. 2004 Feb;47(2):256-7; author reply 257. doi: 10.1007/s10350-003-0022-9. PMID: 15043301.

[17]. KouzminaM,KoljonenV,LeikolaJ,Bo€hlingT,Lant toE. Frequency and locations of systemic metastases in Merkel cell carcinoma by imaging. Acta Radiol Open. 2017;6, 2058460117700449.

[18]. Lemos BD, Storer BE, lyer JG, et al. Pathologic nodal evaluation improves prognostic accuracy in Merkel cell carcinoma: analysis of 5823 cases as the basis of the first consensus staging system. J Am Acad Dermatol. 2010;63:751-761.

[19]. Harms KL, Healy MA, Nghiem P, et al. Analysis of prognostic factors from 9387 Merkel cell carcinoma cases forms the basis for the new 8th edition AJCC Staging System. Ann Surg Oncol. 2016;23:3564-3571.

[20]. 7. Limei Guo, Naoto Kuroda, Eriko Miyazaki, Yulan Jin, Makoto Toi, Tadashi Hamauzu, Makoto Hiroi, Takeshi Inoue, Atsushi Inoue, and Hideaki Enzan. Anal canal neuroendocrine carcinoma with Pagetoid extension. Pathology International 2004;54: 630-635

[21]. E. J. S. Ong, L. M. Wang, J. Darby. Synchronous Merkel cell and squamous cell carcinoma of the anal canal in an HIV-positive patient: a case report. Colorectal Disease 2012, The Association of Coloproctology of Great Britain and Ireland. , 819-820 doi:10.1111/j.14631318.2012.02983.x

[22]. Ohtomo R, Sekine S, Taniguchi H, Tsuda H, Moriya $Y$, Kushima R. Anal canal neuroendocrine carcinoma associated with squamous intraepithelial neoplasia: a human papillomavirus 18-related lesion. Pathol Int. 2012;62(5):356-359. doi:10.1111/j.14401827.2012.02800.x

[23]. 10. Allen PJ, Bowne WB, Jaques DP, Brennan MF, Busam K, Coit DG. Merkel cell carcinoma: prognosis and treatment of patients from a single in stitution. $\mathrm{J} \mathrm{Cl}$ in On col 2005; 23: 23009. 
[24]. Tai PT, Yu E, Winquist E, Hammond A, Stitt L, Tonita J, et al. Chemotherapy in neuroendocrine/Merkel cell carcinoma of the skin: case series and review of 204 cases. J Clin Oncol 2000; 18: 2493-9.

[25]. Jouary T, Leyral C, Dreno B, Doussau A, Sassolas B, Beylot-Barry M, et al. Adjuvant prophylactic regional radiotherapy versus observation in stage I Merkel cell carcinoma: a multicentric prospective randomized study. Ann Oncol 2012; 23: 1074-80.

[26]. National Comprehensive Cancer N. NCCN Guidelines Version 1.2018 Merkel Cell Carcinoma: National comprehensive cancer, network; 2017. [Online] [Cited 2017 December 12]. Available from: URL:https://www.nccn.org/professionals/physici an_gls/pdf/mcc.pdf.

[27]. Amin MB, Greene FL, Edge SB, Compton CC, Gershenwald JE, Brookland RK, et al. The Eighth Edition AJCC Cancer Staging Manual: Continuing to build a bridge from a populationbased to a more "personalized" approach to cancer staging. CA Cancer J Clin 2017; 67: 939.

[28]. Patnaik A, Kang SP, Rasco D, Papadopoulos $\mathrm{KP}$, Elassaiss-Schaap $\mathrm{J}$, Beeram $\mathrm{M}$, et al. Phase I study of pembrolizumab (MK-3475; antiPD-1 monoclonal antibody) in patients with advanced solid tumors. Clin Cancer Res. 2015; 21(19):4286-93. DOI: 10.1158/10780432.CCR-14-2607 [PubMed: 25977344]

[29]. Nghiem, P., Bhatia, S., Daud, A., Friedlander, P., Kluger, H., Kohrt, H., et al. Activity of PD-1 blockade with pembrolizumab as first systemic therapy in patients with advanced Merkel cell carcinoma [abstract]. The European Cancer Congress; September 27; Vienna, Austria. 2015. This early study demonstrated exceptionally high initial response rates

[30]. Pembrolizumab in treating patients with advanced Merkel cell cancer. National Institutes of

Health;

https://clinicaltrials.gov/show/NCT02267603

[Accessed Jan 2016] 